\title{
Upwelling of Deep-seated Fluid in the Sikhote-Alin Region, Far East of the Eurasian Plate
}

\author{
Hitomi Nakamura ${ }^{1}$ (D) Hikaru Iwamori ${ }^{2,3}$. Noritoshi Morikawa ${ }^{1}$. \\ Natalia Kharitonova ${ }^{4,5} \cdot$ Georgy Chelnokov $^{6} \cdot$ Ivan Bragin $^{5} \cdot$ Qing Chang $^{7}$
}

Received: 14 March 2021 / Accepted: 3 September 2021 / Published online: 9 September 2021

(c) The Author(s) 2021

\begin{abstract}
Spring waters with high-pCO $\mathrm{pC}_{2}$ content are widely distributed in the Sikhote-Alin region in Russia. Mukhen spa is one such spring located in the northern Sikhote-Alin region. This spa has two types of upwelling spring waters and exhibits distinct chemical signatures. One of the springs originates from a shallow aquifer and features hydrogen and oxygen isotopic ratios of meteoric water with a high ${ }^{3} \mathrm{He} /{ }^{4} \mathrm{He}$ ratio, whereas the other originates from a deeper aquifer and features a distinctly negative $\delta^{18} \mathrm{O}$ with a lower ${ }^{3} \mathrm{He} /{ }^{4} \mathrm{He}$ ratio. To understand this apparent discrepancy and the water circulation dynamics beneath Mukhen springs, we utilized all published data concerning the major solute elements and isotopic ratios of Mukhen spring waters and compared them with the He isotopic compositions on several springs in the far eastern region, which are newly analyzed in this study. The results show that the shallow aquifer comprises meteoric water that interacts with the crust enhanced by the gas component welling up from deep underground, while the fluid in deep aquifer fingerprinted the hydration reaction of silicate and involves a mantle component possibly delivered by a deep-seated fluid and/or gas upwelling along the tectonic fault through the western margin of the Sikhote-Alin region.
\end{abstract}

Keywords Fluid $\cdot$ Deep-seated $\cdot$ Spring water $\cdot$ REE $\cdot$ Helium $\cdot$ Sikhote-Alin

Hitomi Nakamura

hitomi-nakamura@aist.go.jp

1 Geological Survey of Japan, National Institute of Advanced Industrial Science and Technology (AIST), Ibaraki 305-8567, Japan

2 Earthquake Research Institute, The University of Tokyo, Tokyo 113-0033, Japan

3 Department of Earth and Planetary Sciences, Tokyo Institute of Technology, Tokyo 152-8550, Japan

4 Department of Geology, Moscow State University, Moscow, Russia 119991

5 Far East Geological Institute, Far East Branch, Russian Academy of Sciences, Vladivostok, Russia 690022

6 Geological Institute, Russian Academy of Sciences, Moscow, Russia 119017

7 Volcanoes and Earth's Interior Research Center, Japan Agency for Marine-Earth Science and Technology (JAMSTEC), Kanagawa 237-0061, Japan 


\section{Introduction}

In the Sikhote-Alin region, there are more than 70 upwelling springs called high-pCO $\mathrm{CO}_{2}$ waters (Chelnokov and Kharitonova 2008). The typical signature of these springs is the extraordinary abundance of $\mathrm{CO}_{2}$, which almost saturates cold water. In addition, this phenomenon appears to be confined to the tectonic faults of the Sikhote-Alin fold region. With respect to the genesis of high- $\mathrm{pCO}_{2}$ water, several mechanisms associated with young volcanism have been suggested, and several studies have shown that most high- $\mathrm{pCO}_{2}$ waters have a meteoric origin (Kharitonova et al. 2017). Recently, Kharitonova et al. (2019) observed a high ${ }^{3} \mathrm{He} /{ }^{4} \mathrm{He}$ ratio in the Mukhen springs, indicating that these springs originated from a considerable depth. The He isotopic system is a strong indicator to distinguish the contributions from various sources, particularly those from crustal and mantle rocks. ${ }^{4} \mathrm{He}$ is continuously produced in the surrounding crustal rocks owing to the radioactive decay of uranium and thorium and then dissolves into groundwater over geologic time spans; therefore, the ${ }^{3} \mathrm{He} /{ }^{4} \mathrm{He}$ ratio is useful for investigating the flow regime, age, and origin of groundwater (Morikawa et al. 2008). The mean upper mantle value is determined by compiling the He isotopic ratios in the mid-ocean ridge basalts (MORBs), and typical crustal rock ${ }^{3} \mathrm{He} /{ }^{4} \mathrm{He}$ production ratios are estimated to be significantly lower than the mantle and atmospheric values (Ozima and Podosek 2002). Therefore, the ${ }^{3} \mathrm{He} /{ }^{4} \mathrm{He}$ ratio, including its abundance, directly reflects the nature of $\mathrm{He}$ dissolved in groundwater. However, to date, only a limited number of He isotopic data have been available for the spring waters in the Sikhote-Alin region (Kharitonova et al. 2020). Within this context, we provide new He and $\mathrm{Ne}$ isotopic data to constrain the regional characteristics and origin of the high$\mathrm{pCO}_{2}$ springs in the area.

Unlike the He isotopic data, there are a number of data concerning the $\mathrm{O}-\mathrm{H}$ isotopic systematics. Kharitonova et al. (2020) showed that most high-p $\mathrm{CO}_{2}$ waters along the Sikhote-Alin region have a typical signature plotted on or toward the right/below the Global Meteoric Water Line (GMWL), which is evident in most surface waters, shallow groundwater, sedimentary basin brines, and metamorphic fluids. However, the spring water with high $\mathrm{pCO}_{2}$ at the Mukhen spa shows a distinct negative $\delta^{18} \mathrm{O}$ shift from the GMWL (Kharitonova et al. 2017), which may provide key information on the origin of the water. Although Kharitonova et al. (2017) suggested that such a feature could have been produced by mineral precipitation, the origin of the distinct negative shift needs to be further examined.

For deciphering the water-mineral reactions, rare earth elements (REE) can be a useful indicator (e.g., Nakamura et al. 2015). REE basically serves as a set of elements behaving coherently, and at the same time, with respect to specific conditions, the individual elements may behave differently. For instance, the behaviors of several elements with the potential to be divalent or tetravalent cations in REE, such as $\mathrm{Ce}$ and $\mathrm{Eu}$, are sensitive to the oxidation state, particularly near the surface and/or involvement of specific minerals such as plagioclase. These behaviors of REE, as well as the major solutes in the spring waters, would be useful to discuss the water-mineral reactions, particularly at shallow levels. In this study, by combining the new He and Ne isotopic data and the literature data of major solutes, REE, and $\mathrm{O}-\mathrm{H}$ isotopic ratios, we aim to discuss possible origins of the high- $\mathrm{pCO}_{2}$ springs, in particular the Mukhen spa water in the Sikhote-Alin region. 


\subsection{Study Area and Chemistry of Spring Water}

Mukhen spa is located on the border of the Middle Amur sedimentary basin, which is part of a complex geologic structure, and the large Sikhote-Alin mountain-folded system (Fig. 1). The geological structure of the region is formed by the Mesozoic basement, Oligocene-Miocene sedimentary and volcanic rocks, Pliocene-Lower Quaternary flood basalts, and Quaternary alluvium. The study area contains many fault zones, the largest being the Punchi fault zone, which is approximately 150-200 m. The Punchi catchment area features two different upwelling groundwaters: the $\mathrm{Ca}-\mathrm{Mg}-\mathrm{HCO}_{3}$ and $\mathrm{Na}-\mathrm{HCO}_{3}$ types (Kharitonova et al. 2017). The $\mathrm{Ca}-\mathrm{Mg}-\mathrm{HCO}_{3}$ type is thought to originate from a shallow aquifer located at a depth of $100 \mathrm{~m}$, typically featuring low total dissolved solid (TDS) contents $(<1.7 \mathrm{~g} / \mathrm{L}), \mathrm{pH} 4.9-5.8$, and a $\mathrm{Ca} / \mathrm{Mg}$ molar ratio of approximately 0.94 . On the other hand, the $\mathrm{Na}-\mathrm{HCO}_{3}$ type is considered to well up from a deep aquifer located below $200 \mathrm{~m}$, with a narrow $\mathrm{pH}$ range of 7.2-7.5, and very high TDS contents of up to $14 \mathrm{~g} / \mathrm{L}$. The

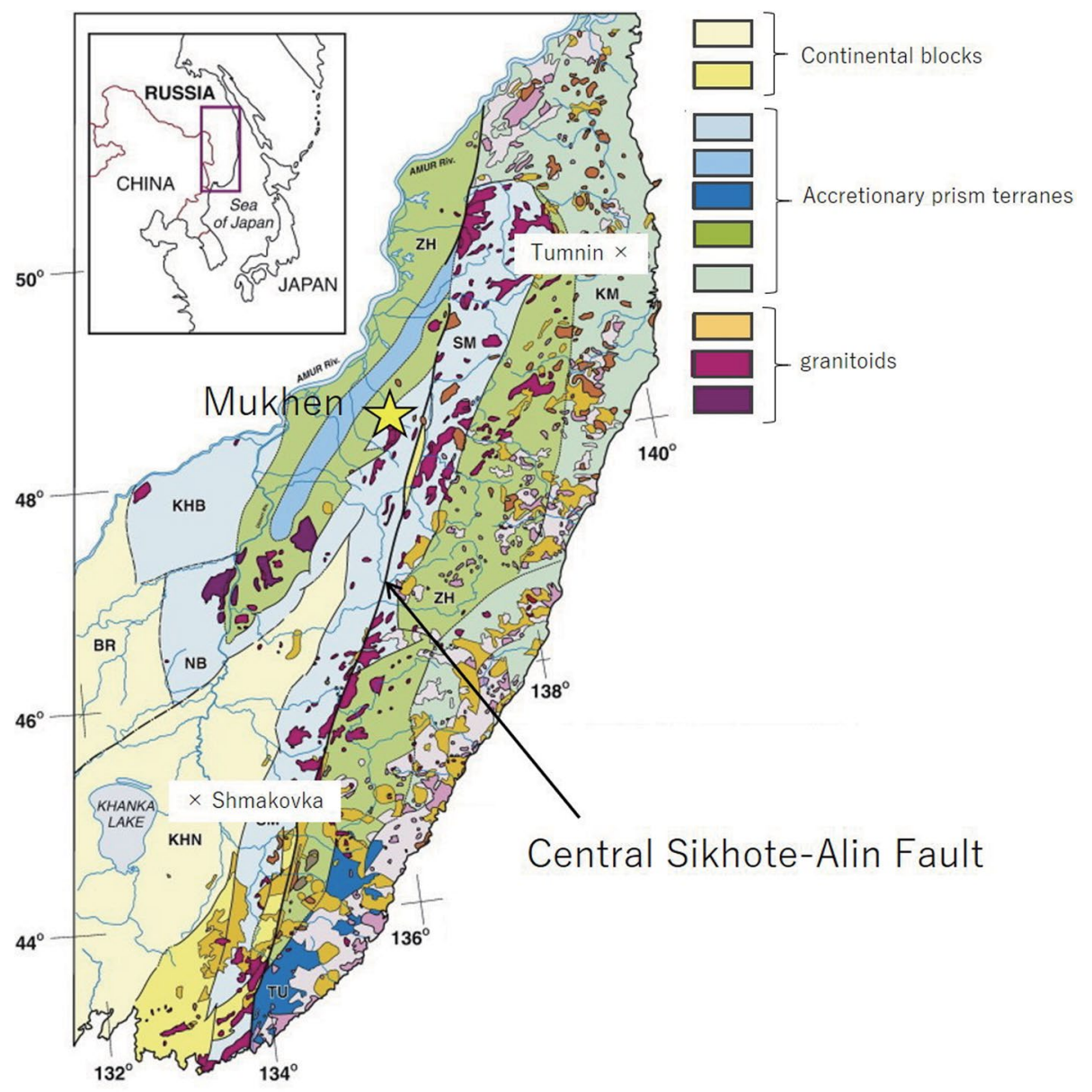

Fig. 1 Locality of the Mukhen spa in Sikhote-Alin mountains, modified after Fig. 1 in Grebennikov et al. (2016). See more detail in Grebennikov et al. (2016) 
$\mathrm{Ca}-\mathrm{Mg}-\mathrm{HCO}_{3}$ type groundwater is attributed to the intense interaction of meteoric waters with bedrock. Conversely, the $\mathrm{Na}-\mathrm{HCO}_{3}$ type groundwater is formed during a long circulation of meteoric waters to deep crustal levels, where interaction with shale, sandstone, and granite bedrock occurs (Kharitonova et al. 2017). Both groundwater types were intermittently monitored over a period of 10 years. Based on the schematic image by Kharitonova et al. (2017), hereafter, we refer to the $\mathrm{Ca}-\mathrm{Mg}-\mathrm{HCO}_{3}$ type groundwater obtained from well 3 as shallow aquifer and the $\mathrm{Na}-\mathrm{HCO}_{3}$ type groundwater obtained from well 30 as deep aquifer in the discussion of the water circulation (Fig. 2).

\subsection{Changes in Water Chemistry Over 20 Years of Two Groundwaters in Mukhen Spa}

Figure 3a shows the changes in $\mathrm{pH}$ and anions in the shallow aquifer from 1992 to 2005 and those in the deep aquifer from 1986 to 2005. The changes in cations such as K, $\mathrm{Mg}, \mathrm{Ca}$, and $\mathrm{Na}$ in the shallow and deep aquifers are shown in Fig. $3 \mathrm{~b}$. The data were obtained from Kharitonova et al. (2017). The surveys were not conducted constantly; however, the changes that occurred over approximately 20 years can be followed. The $\mathrm{pH}$ values were stable over 20 years for both aquifers and kept lower in the shallow aquifer compared to the deep aquifer. The $\mathrm{HCO}_{3}{ }^{-}$contents were stable for both aquifers, whereas the $\mathrm{Cl}$ contents changed differently in each aquifer. In the shallow aquifer, the $\mathrm{Cl}$ content was low and had decreased for 10 years, while in the deep aquifer, $>10$ times higher $\mathrm{Cl}$ content was stably observed. The $\mathrm{SO}_{4}{ }^{2-}$ content was unstable but relatively high in the deep aquifer. This tendency, low in the shallow and high in the deep aquifers,

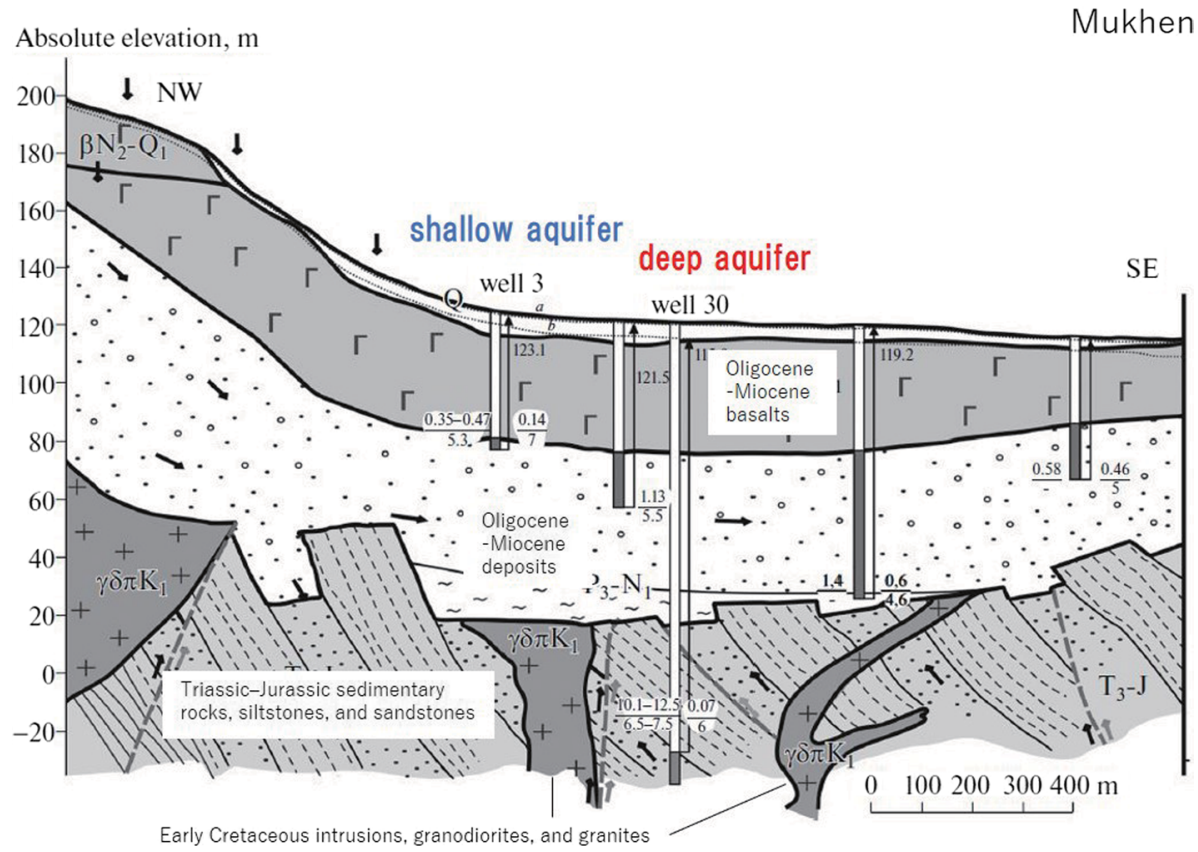

Fig. 2 Schematic hydrological section of the Mukhen spa modified after Fig. 2 in Kharitonova et al. (2017). The well 3 and 30 are equal to shallow and deep aquifers in this study, respectively. See more detail in Kharitonova et al. (2017) 
(a)
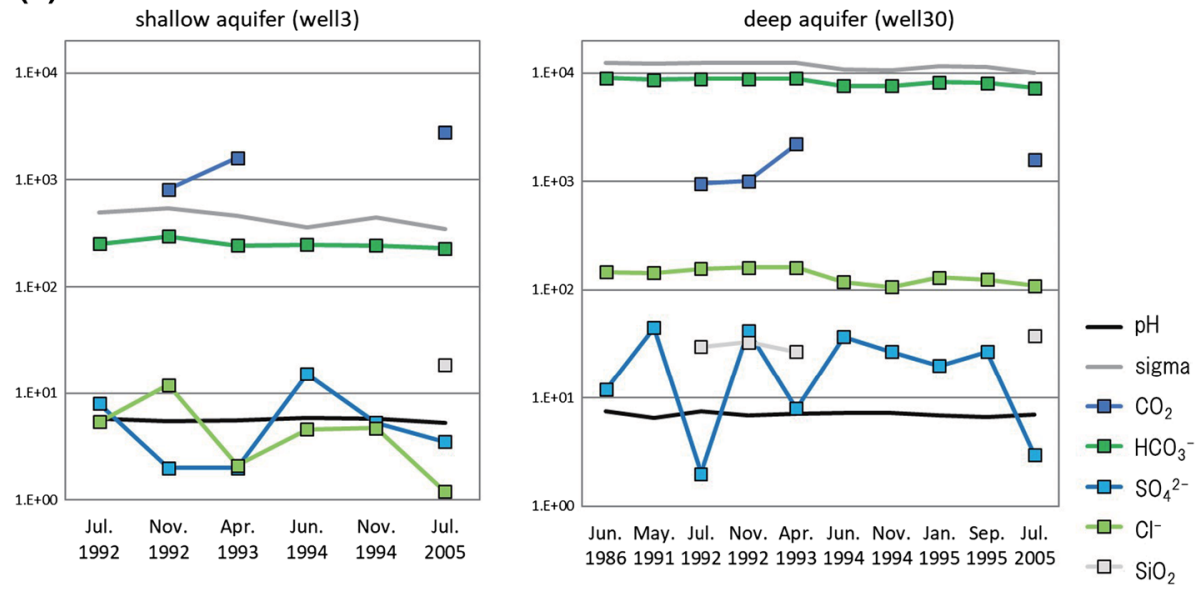

(b)
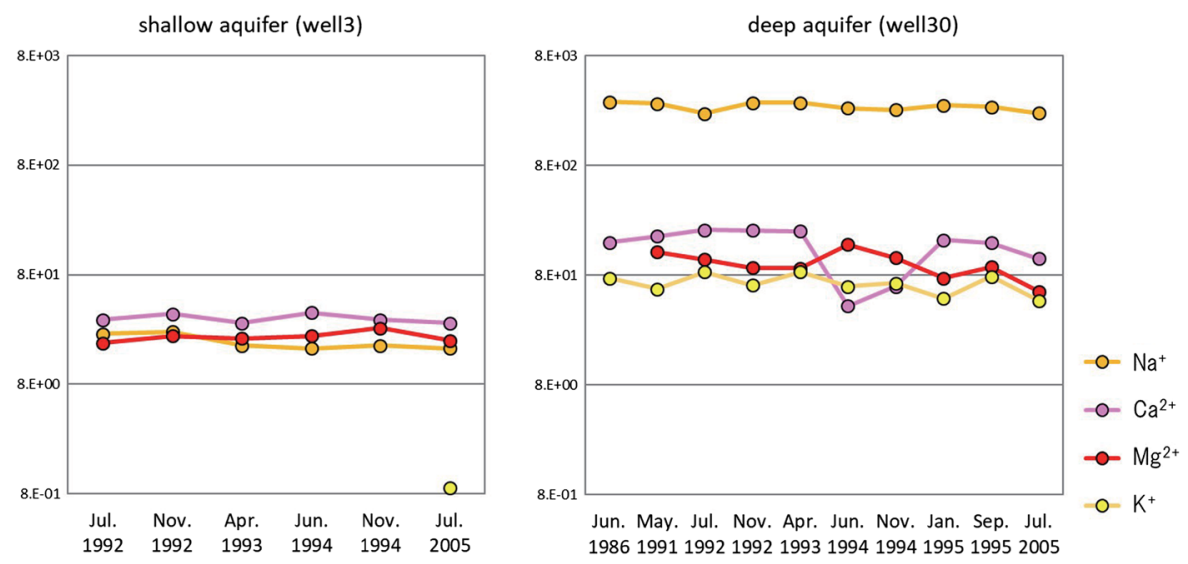

Fig. 3 a Changes of $\mathrm{pH}$ and anions (mg/l) in the shallow aquifer from 1992 to 2005 and those in the deep aquifer from 1986 to 2005 . To compare all data, the vertical axis is shown in logarithm. Sigma is a sum of ions. The data are summarized in Table 1 from Kharitonova et al. (2017). b Changes of cations (mg/l) in the shallow aquifer from 1992 to 2005 and those in the deep aquifer from 1986 to 2005. To compare all data, the vertical axis is shown in logarithm. The data are summarized in Table 1 from Kharitonova et al. (2017)

was also observed in the cations, $\mathrm{Na}, \mathrm{K}, \mathrm{Ca}$, and $\mathrm{Mg}$, as shown in Fig. 3b. Although the $\mathrm{K}$ value has not been reported except in 2005, $\mathrm{Na}, \mathrm{Ca}$, and $\mathrm{Mg}$ are almost stable in the shallow aquifer. In the deep aquifer, these cations are almost stable for 20 years, and their contents increase in the following order: K, Mg, Ca, and $\mathrm{Na}$. In 1994, the Ca content suddenly dropped below the K content and then recovered in 1995 . This sudden change was seemingly accompanied by the changes in anion content, such as $\mathrm{Cl}, \mathrm{CO}_{2}$, and $\mathrm{SO}_{4}{ }^{2-}$. The changes in anion content were not large; however, $\mathrm{Cl}$ content was low in 1994 , indicating a change in the input of saline water into the deep aquifer. The data are summarized in Table 1. 


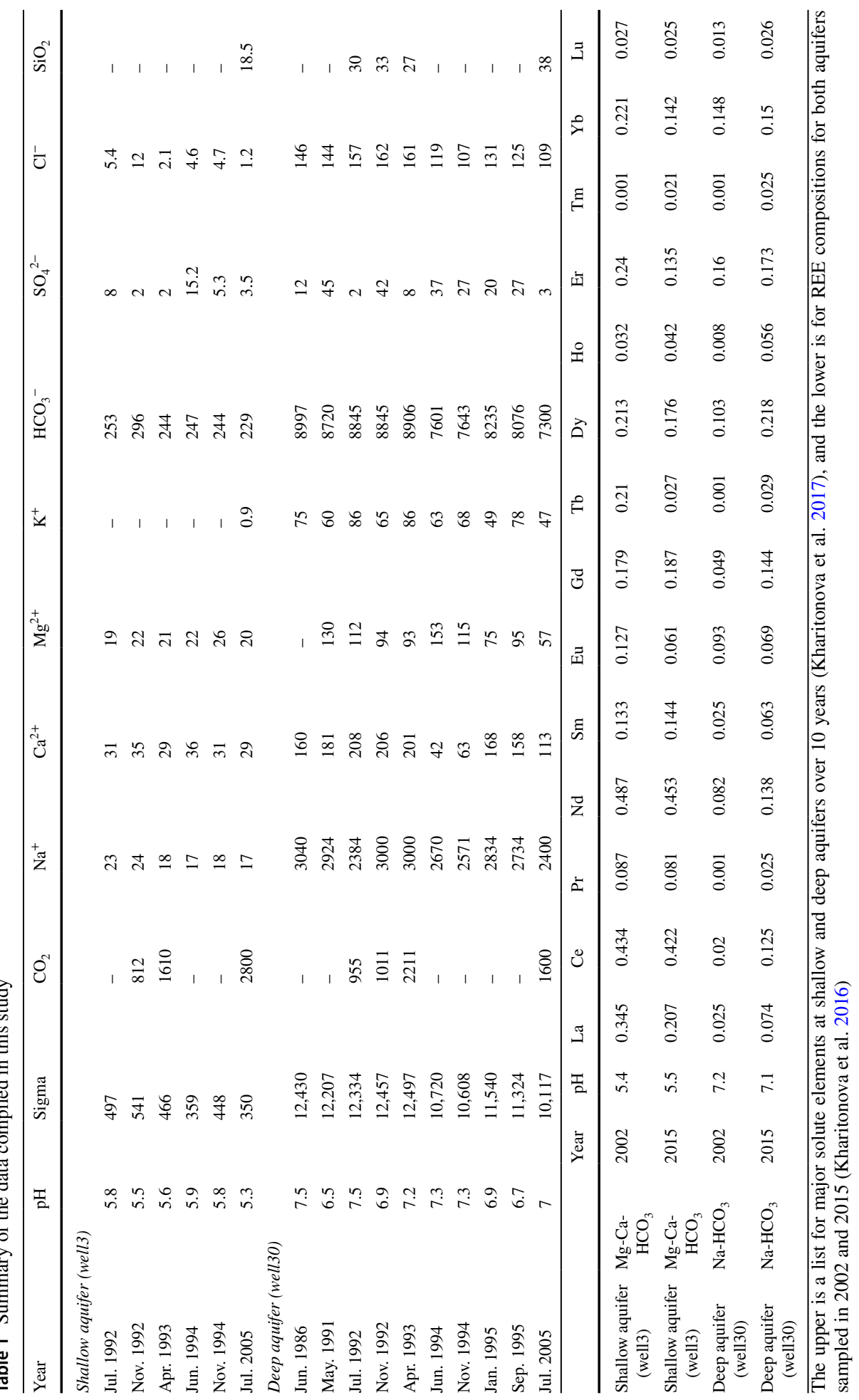


Fig. $4 \mathrm{O}-\mathrm{H}$ isotopic compositions of the shallow (marked with orange circle) and the deep (marked with blue circle) aquifers in Mukhen compared with the springs in the Sikhote-Alin region, modified after Kharitonova et al. (2017). The data of Annesky and Tumnin located in the far eastern region are from Bragin et al. (2016)

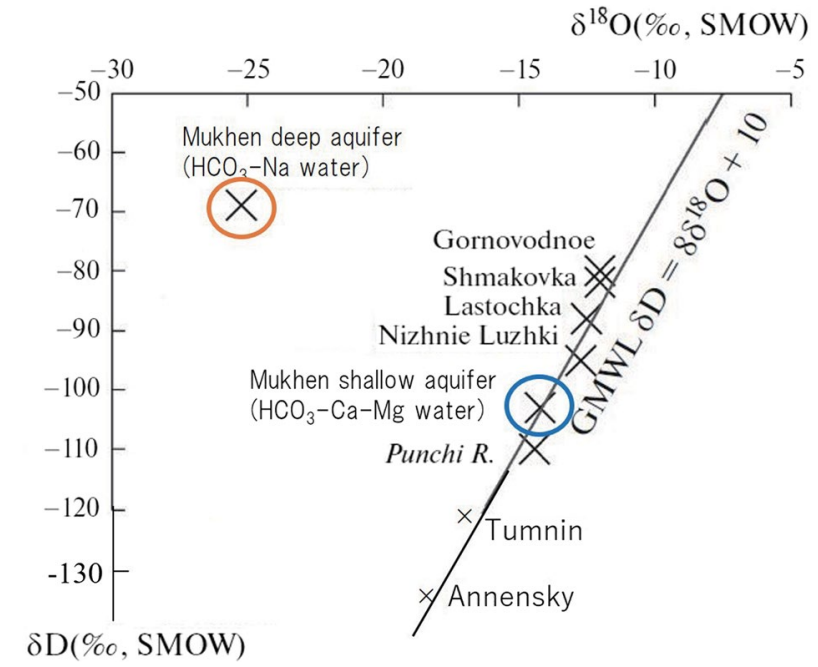

\subsection{Distinct Isotopic Features of Two Groundwaters in Mukhen Spa}

In Fig. 4, the O-H isotopic compositions of the waters in both shallow and deep aquifers of the Mukhen springs are compared with those of the representative springs in the Sikhote-Alin region (Kharitonova et al., 2017) and two springs (Tumnin and Annesky) in the far eastern region (Bragin et al. 2016). The shallow aquifer in Mukhen and the other springs in the Sikhote-Alin region and the far eastern region have O-H isotopic ratios plotted on/around the GMWL, whereas the deep aquifer had a distinct $\mathrm{O}-\mathrm{H}$ isotopic ratio plotted on far left/far above the GMWL.

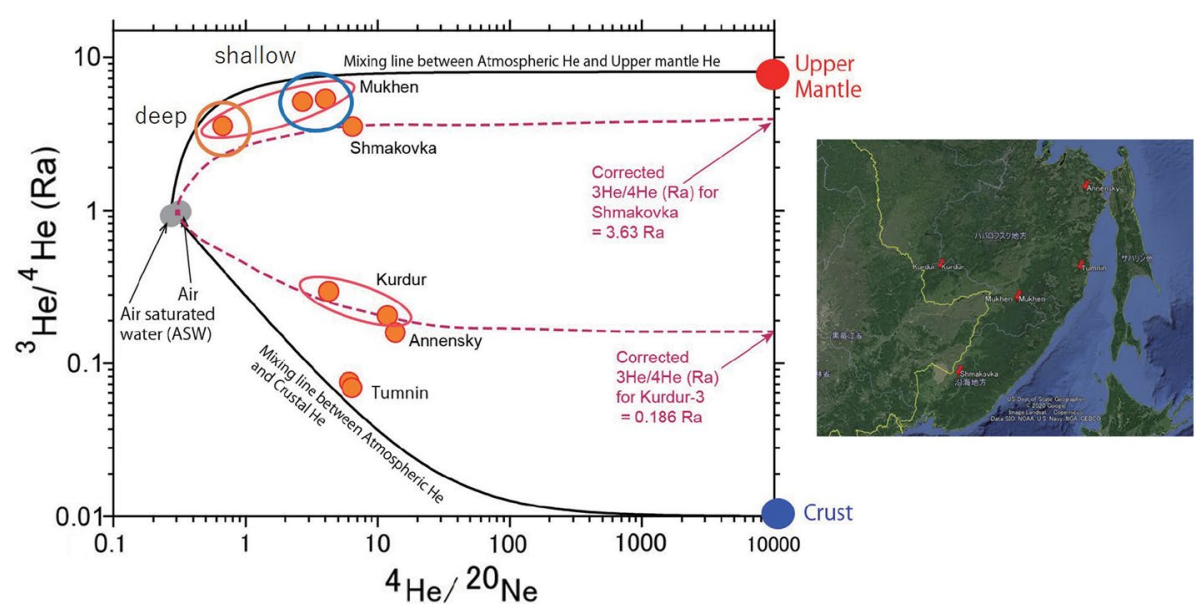

Fig. $5 \mathrm{He}$ isotopic compositions of the shallow (marked with orange circle) and the deep (marked with blue circle) aquifers in Mukhen compared with the springs in the far eastern region. The data are listed in Table 2. The inset shows the locality of each spring used here 


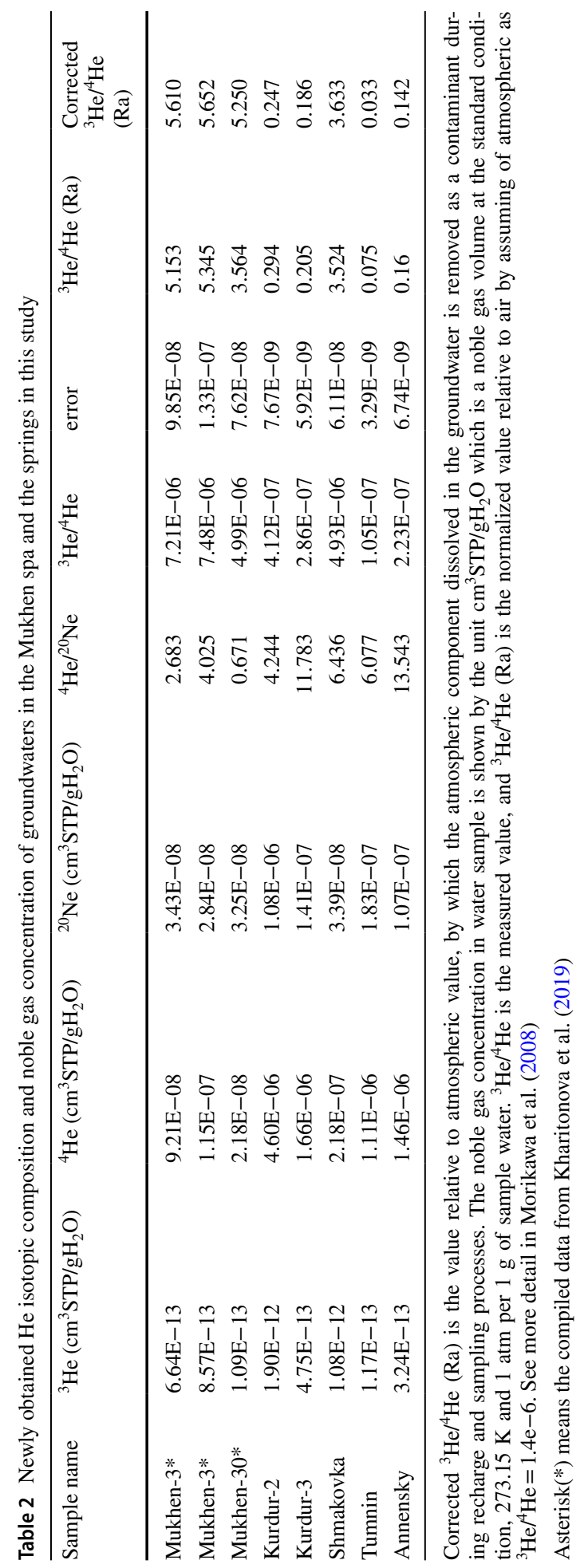


In Fig. 5, the He isotopic compositions are shown for both aquifers in the Mukhen springs (Kharitonova et al. 2019), compared with the newly obtained data by this study for several springs in the far eastern region (Table 2). The locations of the springs are shown in the inset of Fig. 5. Mukhen and Shmakovka are located in the Sikhote-Alin region, and Tumnin and Annesky in the far eastern region, while Kurdur is located in a more continental region. The ${ }^{3} \mathrm{He} /{ }^{4} \mathrm{He}(\mathrm{Ra})$ in the figure is the value normalized by air to identify the effect of deep mantle or shallow crustal material. In the case of high air contamination inferred from the low ${ }^{4} \mathrm{He} /{ }^{20} \mathrm{Ne}$ ratio, the ${ }^{3} \mathrm{He} /{ }^{4} \mathrm{He}$ (Ra) should be recalculated as corrected ${ }^{3} \mathrm{He} /{ }^{4} \mathrm{He}(\mathrm{Ra})$.

For instance, Shmakovka and Kurdur-3 in the figure were recalculated by removing the value of air contamination. When the value of ${ }^{4} \mathrm{He} /{ }^{20} \mathrm{Ne}$ is closer to the air-saturated water in the figure, the error becomes significant. The relevant equations and details are provided by Morikawa et al. (2016). The data of Mukhen and Shmakovka are plotted against a combination of the upper mantle and atmospheric component, and a high contribution from the mantle is identified. The data of Kurdur, Annensky, and Tumnin are plotted against a combination of the crust and atmospheric components, indicating contribution from the crustal level. Indeed, the upper mantle signature seems to be observed only in the SikhoteAlin region.

Concerning the two aquifers in the Mukhen springs, the ${ }^{3} \mathrm{He} /{ }^{4} \mathrm{He}(\mathrm{Ra})$ is clearly different: high in the shallow aquifer and low in the deep aquifer (Fig. 5, Table 2). Therefore, relatively deep mantle signatures were inversely observed in the shallow aquifer. However, this observation was consistent with that of the gas component. In Fig. 6, the gas compositions of $\mathrm{N}_{2}$ and $\mathrm{O}_{2}$ are shown for both aquifers. $\mathrm{CO}_{2}$ is the main component in more than $99 \%$ of the gas, and no clear difference was observed in both aquifers. The $\mathrm{N}_{2}$ and $\mathrm{O}_{2}$ components were relatively high in the shallow aquifer (Fig. 6). Considering the He isotopic ratio (Fig. 5), at least a part of the light gas components, which involves a mantle signature, are likely delivered through cracks or veins without much interaction with the crustal materials and have been gathered and stacked in the shallow aquifer.

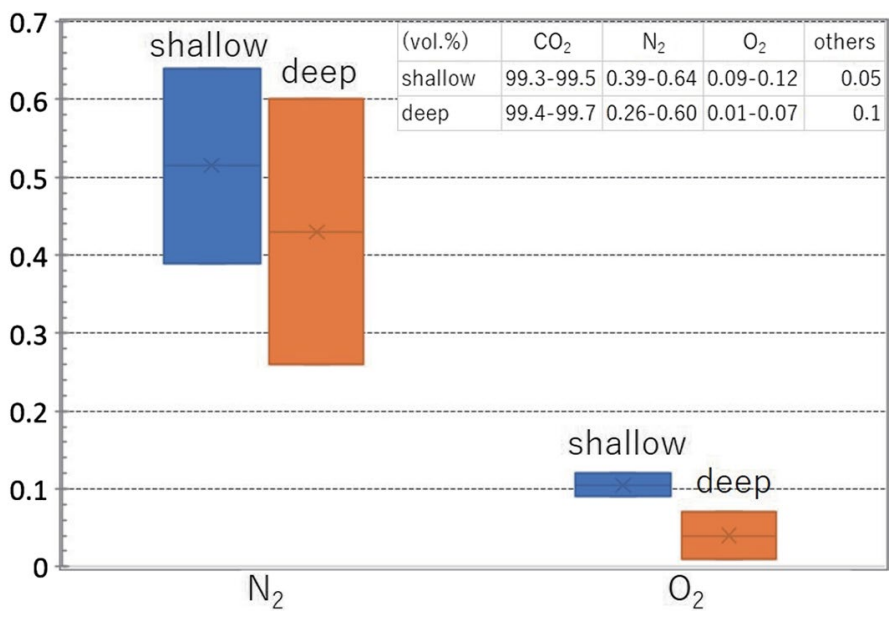

Fig. 6 Range of gas content (in vol.\%) in the shallow and the deep aquifers in the Mukhen spa. The inset is data from Kharitonova et al. (2017) 


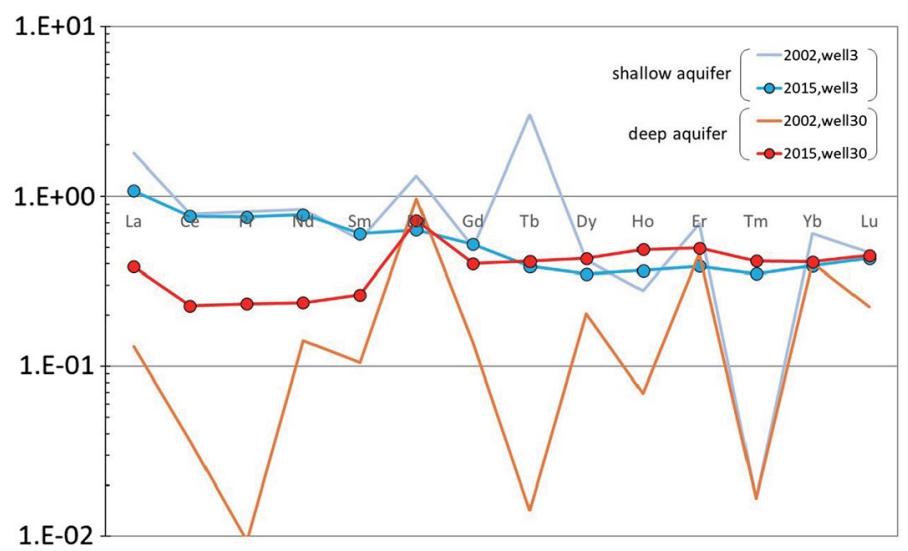

Fig. 7 Change of rare earth element compositions of shallow and deep aquifers in Mukhen, sampled in 2002 and 2015. The abundance of REE is normalized by depleted MORB mantle (DMM) and shown in logarithm. The data are summarized in Table 1 from Kharitonova et al. (2016)

\subsection{REE Patterns of Two Groundwaters in Mukhen Spa}

In Fig. 7, the rare earth compositions of both shallow and deep aquifers in 2002 and 2015 (Kharitonova et al. 2016) were normalized by using the depleted MORB mantle (DMM) for comparison with the mantle source. Each aquifer evidently yielded a different pattern (Fig. 7). In the shallow aquifer, the REE abundances were relatively high in both 2002 and 2015, whereas they were low in the deep aquifer for both years. In the shallow aquifer, the flat high pattern with a slight increase in light rare earth elements (LREE), accompanying several anomalies, was observed in 2002 . However, the anomalies as positive- $\mathrm{Tb}$, negative$\mathrm{Tm}$, and negative-Ho were only observed in 2002, and disappeared in 2015 (Fig. 7). In 2015, an almost flat high pattern with increasing LREE was observed without any anomaly. When samples were obtained between these two years, an input of dense water would have occurred and refreshed the shallow aquifer. In the deep aquifer, a convex-down pattern with several anomalies, representatively in europium (Eu), was observed in 2002. This pattern disappeared in 2015 and changed to an almost flat or slightly convex-down pattern with decreasing LREE. Though Data on REE are insufficient, the change over these two years during which samples were collected is obvious. In addition, the differences between these two aquifers are clear and should be explained to elucidate the system.

\section{Discussion}

\subsection{Possible Mechanism in Two Aquifers}

A convex-down signature with increased LREE and HREE and a positive spike of Eu, a W-shaped pattern, is often observed in certain spring waters (Nakamura et al. 2015, 2016). This W-shaped pattern is thought to be caused by the precipitation of Fe oxide (Kawabe 2015). When the redox conditions are changed drastically, such as meteoric water flowin (Iwamori et al. 2020), the mid-REEs tend to be co-precipitated with iron hydro-oxide, which results in the depletion of mid-REEs compared to LREEs and HREEs in the residual 
fluid phase. In addition, the Eu anomaly from feldspar-like plagioclase abundant in crustal rocks is added to the mid-REE depletion, which leads to a $\mathrm{W}$-shaped pattern in the residual fluid.

The above processes can be observed in the Arima spa located on the edge of the Arima-Takatsuki fault in western Japan. This spa is distinct as it contains a fluid coming from subducted Philippine Sea plate. Various springs are gathered in a narrow $1 \mathrm{~km}^{2}$ area. A W-shaped pattern is observed in the dominant type of spring waters in Arima as a remnant after precipitation. Simultaneously, a flat high REE pattern with a small positive Eu anomaly is observed in the relevant spring water named Kinsen, whereas a flat high REE pattern with a small negative Eu anomaly is observed in the relevant spring water Tansansen. The former is thought to be generated by the brine almost directly welling up from the subducted slab through the mantle, whereas the latter is generated by the interaction between the crust and meteoric water enhanced by deep-originated gas.

From the perspective of the $\mathrm{W}$-shaped pattern, the change in the two aquifers over two years is distinct. In 2002, a strong W-shaped pattern was observed in the deep aquifer, while a basically flat signature with several anomalies was observed in the shallow aquifer. However, in 2015, their REE patterns came into close proximity but still differed, in particular, on the decreasing trend toward LREE in the deep aquifer. This difference between two aquifers in 2002 indicates no direct interaction of water among these aquifers. Instead, they isolated each other over the long term, which is consistent with the stable chemical composition of the major solute elements (Fig. 3ab). Therefore, the trend in the shallow aquifer is thought to be caused by the interaction with crustal material. The genesis of water in the shallow aquifer is basically similar to that in Tansansen, Arima, in which meteoric water interacts with crustal material consisting of the aquifer where gas coming from the deep underground enhances carbonic acidity to potentially dissolve elements including REEs from surrounding crust. This mechanism has been maintained for over 10 years at least because the REE abundance in the shallow aquifer is almost the same, and the REE pattern was basically stable in both 2002 and 2015. However, several anomalies were observed in $\mathrm{Eu}, \mathrm{Tb}$, and Ho. Therefore, the strong interaction between meteoric water and surrounding rocks, enhanced by the accumulated gas welling up from deep underground, is the mechanism for the genesis of water in shallow aquifers. This would be a common scenario of water with high-pCO $\mathrm{pO}_{2}$ content widely upwelling along Shikhote-Alin. Alternatively, in the deep aquifer, the change in the REE pattern is clear and distinct. The decreasing trend toward LREE in the deep aquifer that appeared in 2015 was unique, which is consistent with that of clay minerals such as kaolinite and smectite, as reported in the altered basalts (Desprairies et al. 2006).

\subsection{Negative 0-Shift Only in the Deep Aquifer}

The most distinct signature in Mukhen springs was the negative $\delta^{18} \mathrm{O}$ shift observed only in the deep aquifer, as shown in Fig. 4. Furthermore, other springs in the far eastern region, including the Sikhote-Alin region, were plotted on the GMWL. This signature is not commonly observed in groundwater but sometimes occurs, as reported in several studies (Warr et al. 2021). Warr et al. (2021) compiled and showed that the $\delta^{18} \mathrm{O}$ and $\delta^{2} \mathrm{H}$ values for specific fluids from Precambrian shield sites worldwide are typically plotted along the left or above the GMWL. They suggest an isotopic exchange between the primary fluid and the host rocks occurring under low temperature and low water-rock ratios over long (Ma) geological timescales, which creates a common signature progressive ${ }^{18} \mathrm{O}$ depletion in the 
fluids over time, while $\delta^{2} \mathrm{H}$ values are less affected, despite differences in geologic settings. Although the distinct value of the $\mathrm{O}-\mathrm{H}$ isotopic ratio in the deep aquifer of Mukhen spa is outside the reported area of the Precambrian shield sites, Precambrian rocks at depth possibly contributed to the genesis of fluid in Mukhen spa based on geological outcrops exposed in the far eastern region. Indeed, an alteration including silicate hydration at low temperatures can reasonably explain the distinct $\mathrm{O}-\mathrm{H}$ signature in the deep aquifer (Clark and Fritz 1997). This reaction occurs when the condition meets (i) very low water-rock ratios where the rock reservoir dominates in exchange reactions, and (ii) geological time scales, which slows down the exchange rate and hydration at low temperatures (Clark and Fritz 1997). In particular, the isotopic fractionation of ${ }^{18} \mathrm{O}$ between clay minerals and fluids is 15 to $30 \%$ o at $25{ }^{\circ} \mathrm{C}$, while ${ }^{2} \mathrm{H}$ is reversely fractionated into the water at -30 to $-60 \%$. This leads to a severe depletion in ${ }^{18} \mathrm{O}$ and an enrichment in ${ }^{2} \mathrm{H}$ in the fluid, which can reasonably explain the fractionation (approximately -10 in $\delta^{18} \mathrm{O}$ and $+30 \mathrm{in} \delta \mathrm{D}$ ) in the deep aquifer from the meteoric water in this region. In such a case, the meteoric aquifer is occupied by saline water welling up from deep underground, which is consistent with the unique REE pattern of the deep aquifer in 2015.

\subsection{Possible Origin of Deep Fluid in Mukhen Spa}

Based on these water chemistries, we noticed that these spring waters are changed in the short term, such as 10 years or less. If there was no flow from deep underground and the springs were isolated as a closed system, no change would occur. If only meteoric water circulates, the chemical changes cannot be explained. We presume that the water-rock interaction in the long term would create a thick wall that already interacted with groundwater; therefore, the chromatographic effect should be considered as an explanation of these changes directly reflecting the character of deep waters. In addition, the He isotope characteristics support the idea that a fresh fluid flux intermittently connects from deep underground. The gas component in the deep aquifer moves toward the surface owing to its buoyancy and is stored in the shallow aquifer covered by confining basaltic bedrock. As a result, the He isotopic signature of the shallow aquifer strongly indicates deep-origin water compared to the deep aquifer (Fig. 5). This scenario is also robust in the Arima springs, Tansansen, where water wells up from a shallow aquifer showing a He isotopic ratio that is considerably high, whereas Kinsen where waters well up from the subducted slab through the mantle show a high He isotopic ratio that is, however, lower than that of Tansansen, partly due to the gas release to the shallower aquifer (Kusuda et al., 2014; Nakamura et al., 2015). With respect to Mukhen spa, the reason for the relatively low He isotopes in the deep aquifer would involve processes similar to the Arima spring waters, in addition to the contribution from a silicate component, such as clay minerals. This is consistent with the strong W-shaped pattern of REE in deep aquifers, especially in 2002. A strong W-shaped pattern occurs when the fluid encounters a meteoric aquifer owing to a drastic change in the redox condition. This meteoric aquifer must be something special like a cavity to make precipitation and maintain a long residence time of the fracture fluid at a high degree of low-temperature isotopic exchange with host rocks. The geological barrier between these two aquifers remains stable and robust while maintaining a supply of only gas components toward the surface. In addition, the cap rock above the shallow aquifer works effectively, trapping the gas component from the deep underground. This hydrogeological system isolates from the surface hydrological cycle over the long term. In particular, the existence of mantle component observed in the deep aquifer indicates a possibility of deep-seated fluid 
and/or gas upwelling along the central Sikhote-Alin fault dipping westward. The granitoids outcropped in the Sikhote-Alin region are thought to result in the asthenospheric diapirs through slab window (Grebennikov et al. 2016). The remnant of the slab window may provide a passage of mantle component toward the Mukhen spa.

\section{Conclusion}

Based on the new He and Ne isotopic data and the literature data of major solutes, REE, and $\mathrm{O}-\mathrm{H}$ isotopic ratios, we discussed the possible origins of the high- $\mathrm{pCO}_{2}$ springs, particularly the Mukhen spa water in the Sikhote-Alin region. As in the shallow aquifer in Mukhen, we have newly found that the origin of the high- $\mathrm{pCO}_{2}$ content water upwelling widely in the Sikhote-Alin region basically resembles that of Tansansen in Arima, which interacted with the crust enhanced by gas components welling up from deep underground. In the deep aquifer in Mukhen, the fluid is unique and has a high- $\mathrm{Cl}$ content, a negative shift in $\delta^{18} \mathrm{O}$, and a high-He isotope, which is generated by silicate hydration. However, the possible dominance of the contribution from Precambrian shield rock or the special local structure such as a dominant cavity in the deep aquifer in Mukhen is unclear. If the former is correct, there must be other springs in the Sikhote-Alin region with this distinct character, as representatively observed in the negative ${ }^{18} \mathrm{O}$ shift. Therefore, we recommend a seismic survey on this site and/or water chemistry monitoring to elucidate the upwelling of deep-seated fluid because of the uniqueness of the chemical changes in deep aquifers. In addition, asthenospheric upwelling through the remnant of slab window may provide a passage of mantle component toward the Mukhen spa.

Acknowledgements The authors would like to thank Dr. M. Takahashi, Dr. T. Nishizawa, and Ms. N. Ekimova for their support and advice concerning this study. We also thank the Mukhen spa keepers for their help and advice on the field. Finally, we would like to thank Editage (www.editage.com) for English language editing.

Funding This work was supported by JSPS KAKENHI [Grant Numbers: 17KK0018; JPJSBP120194830] from Japan Society for the Promotion of Science (JSPS).

Open Access This article is licensed under a Creative Commons Attribution 4.0 International License, which permits use, sharing, adaptation, distribution and reproduction in any medium or format, as long as you give appropriate credit to the original author(s) and the source, provide a link to the Creative Commons licence, and indicate if changes were made. The images or other third party material in this article are included in the article's Creative Commons licence, unless indicated otherwise in a credit line to the material. If material is not included in the article's Creative Commons licence and your intended use is not permitted by statutory regulation or exceeds the permitted use, you will need to obtain permission directly from the copyright holder. To view a copy of this licence, visit http://creativecommons.org/licenses/by/4.0/.

\section{References}

Chelnokov GA, Kharitonova NA (2008) Carbonated mineral waters in the South of Russia's Far East (Dal'Nauka, Vladivostok, 2008)

Clark I, Fritz P (1997) Environmental isotopes in hydrogeology, Lewis Publishers. doi:https://doi.org/10. 1201/9781482242911, Edition: 1Publisher: Publishers, L.ISBN: 1-56670-249-6

Desprairies A, Bonnot-Courtois C, Jehanno C, Vernhet S (2006) Mineralogy and geochemistry of alteration products in Leg 81 basalts. Deep Sea Drilling Project Initial Reports, 81 
Grebennikov AV, Khanchuk AI, Gonevchuk VG, Kovalenko SV (2016) Cretaceous and Paleogene granitoid suites of the Sikhote-Alin area (Far East Russia): geochemistry and tectonic implications. Lithos 261:250-261. https://doi.org/10.1016/j.lithos.2015.12.020

Iwamori H, Nakamura H, Chang Q, Morikawa N, Haraguchi S (2020) Multivariate statistical analyses of rare earth element compositions of spring waters from the Arima and Kii areas. Southwest Japan Geochem J 54(4):165-182. https://doi.org/10.2343/geochemj.2.0583

Kawabe I (2015) Lanthanide chemistry, The University of Nagoya Press

Kharitonova NA, Vakh EA, Chelnokov GA, Chudaev OV, Aleksandrov IA, Bragin IV (2016) REE Geochemistry in groundwater of the Silhote Alin Fold Region (Russian Far East). Russ J Pacific Geol 10(2):141-154. https://doi.org/10.1134/S1819714016020032

Kharitonova N, Chelnokov G, Bragin I, Nakamura H, Iwamori H, Morikawa N, Korzun A (2019). E3S web of conferences, 98, WRI-16, https://doi.org/10.1051/e3sconf/20199801025

Kharitonova NA, Shvartsev SL, Lepokurova OE, Chelnokov GA (2017) Unique $\mathrm{CO}_{2}-\mathrm{saturated} \mathrm{mineral}$ waters of the Mukhen Deposit (Khabarovsk Krai): composition and genesis. Dokl Earth Sci 475:953957. https://doi.org/10.1134/S1028334X17080220

Kharitonova NA, Chelnokov GA, Bragin IV, Chudaev OV, Shand P, Funikova VV (2020) Major and trace element geochemistry of CO2-rich groundwater in the volcanic aquifer system of the Eastern SikhoteAlin (Russia). Environ Earth Sci 79:55. https://doi.org/10.1007/s12665-019-8697-y

Kusuda C, Iwamori H, Nakamura H, Kazahaya K, Morikawa N (2014) Arima hot spring waters as a deep-seated brine from subducting slab. Earth Planets Space 66:119. https://doi.org/10.1186/ 1880-5981-66-119

Morikawa N, Kazahaya K, Masuda H, Ohwada M, Nakama A, Nagao K, Sumino H (2008) Relationship between geological structure and helium isotopes in deep groundwater from the Osaka Basin: application to deep groundwater hydrology. Geochem J 42:61-74

Morikawa N, Kazahaya K, Takahashi M, Inamura A, Takahashi HA, Yasuhara M, Ohwada M, Sato T, Nakama A, Handa H, Sumino H, Nagao K (2016) Widespread distribution of ascending fluids transporting mantle helium in the fore-arc region and their upwelling processes: noble gas and major element composition of deep groundwater in the Kii Peninsula, southwest Japan. Geochim Cosmochim Acta 182:173-196

Nakamura H, Chiba K, Chang Q, Nakai S, Kazahaya K, Iwamori H (2015) Rare earth elements of the Arima Spring Waters, Southwest Japan: implications for fluid-crust interaction during ascent of deep brine. J Geol Geophys 04:217. https://doi.org/10.4172/jgg.1000217

Ozima M, Podosek FA (2002) Noble gas geochemistry. Cambridge University Press, Cambridge

Warr O, Giunta T, Onstott TC, Kieft TL, Harris RL, Nisson DM, Lollar BS (2021) The role of low-temperature ${ }^{18} \mathrm{O}$ exchange in the isotopic evolution of deep subsurface fluids. Chem Geol. https://doi.org/10. 1016/j.chemgeo.2020.120027

Publisher's Note Springer Nature remains neutral with regard to jurisdictional claims in published maps and institutional affiliations. 